\title{
EFFECT OF REMINERALIZING AGENTS ON BOND STRENGTH OF RESIN COMPOSITE TO DENTIN: AN IN-VITRO STUDY
}

\author{
M. Rabee*, K. Nomaan ${ }^{* *}$, A. Abdelhady**
}

\begin{abstract}
Objective: The objective of this study was to evaluate the effect of remineralizing agents on bond strength of resin composite to dentin with different adhesive systems after different storage times. Materials and methods: Twentyfour molars with flat occlusal dentin surfaces were prepared. These molars were randomly divided, according to the type of the remineralizing agents, into four main groups: nano hydroxyapatite (A), sodium fluoride (B), fluoro-hydroxyapatite (C) and control group (D); 6 specimens per group. Each group was subdivided into two equal subgroups, 3 molars each, according to the type of adhesive system, into Adper Easy One (subgroup E) and Adper Single Bond (subgroup T). Each subgroup was further subdivided into three divisions according to storage time into one day storage (S1), one month storage (S2) and three months storage (S3). Five specimens were obtained from each division, making a total of 120 specimens. Results: Different remineralizing agents and adhesive systems produced significant effect on mean micro shear bond strength ( $\mathrm{p}=.027 \mathrm{and} \mathrm{p}=.001$ respectively). Also, storage time had a significant effect on micro shear bond strength (MPa) where $(\mathrm{p}=0.027$ ). Conclusion: Remineralizing agents can be used successfully under resin composite restorative material. Storage time has a positive effect on the bond strength between dentin and resin composite.
\end{abstract}

KEY WORDS: Bond strength, Remineralizing dentine, Composite resin

\section{INTRODUCTION}

Dentin hypersensitivity has a prevalence around $25 \%$ of population. It is mainly caused by exposed dentin as a result of enamel loss and/or gingival root surface exposure from attrition, abrasion, erosion, or wedge-shaped defects. Also, iatrogenicinduced dentin sensitivity, after placement of direct or indirect restorations on vital teeth, is a common clinical phenomenon. Dentin hypersensitivity is possibly provoked by an abnormal flow of dentinal tubules' fluid due to external stimuli ${ }^{(1,2)}$.

Treatment for hypersensitive dentin involves occlusion of dentinal tubules, application of sedative agents, and promotion of dentin remineralization. It is generally recognized that dentin hypersensitivity is inhibited by precipitation of water-insoluble substances at the entrance or inside the dentinal tubules. Some ingredients contained in dentin desensitizers may induce chemical interaction with dentin organic substances, and such modification may also affect sealing and bonding characteristics of luting agents ${ }^{(3)}$.

It was advocated that sealing open tubules with a calcium-containing dentin-like substance would increase wear resistance and acid resistance by blocking diffusion through the tubules ${ }^{(4)}$.

Hydroxyapatite has long been among the most-studied biomaterials in the medical field for both its proven biocompatibility and for being the main constituent of the mineral part of bone and teeth. Hydroxyapatite is also an important source of calcium and phosphate, very important for the remineralization of demineralized dentin parts ${ }^{(5,6)}$.

\footnotetext{
* Demonstrator, Operative Department, Faculty of Dental Medicine, Al-Azhar University-Cairo.

** Professor, Operative Department, Faculty of Dental Medicine, Al-Azhar University-Cairo.

*** Lecturer, Operative Department, Faculty of Dental Medicine, Al-Azhar University-Cairo.
} 
Treatment of the exposed root surfaces with sodium fluoride toothpaste and concentrated fluoride solutions is very efficient in managing dentinal hypersensitivity. The mode of action appears to be through the induction of high mineral content which create a calcific barrier blocking the tubular openings on the dentine surface. New introduced material is fluoro-hydroxyapatite this material aimed to have the advantages of both hydroxyapatite and fluoride ${ }^{(7,8)}$.

Two strategies of dental adhesion are often used; total etch and self-etch. From biological viewpoint, mechanisms of action are quite different for these strategies. In case of total etch, removal of the smear layer is the main action of etchant gel followed by the diffusion of adhesive into open dentinal tubules and demineralized collagen fibrils. Meanwhile, selfetch strategy depends on remodeling of the smear layer where simultaneous etching and diffusion occurs $^{(1,8)}$.

Shear bond strength is one of the important factors in efficiency and quality of adhesive systems because of its essential role in bonding composite to dental tissue. Inadequate shear bond strength causes early failure of restoration in the face of minimum masticatory forces ${ }^{(9)}$.

The use of remineralizing agents may affect bonding between dentin and luting materials. Durable bonding between dentin and luting materials, in such cases is one of the most important factors for avoiding detachment of the restorations as well as the prevention of microleakage, secondary dental caries and tooth fracture ${ }^{(10)}$. The hypothesis of this study is to evaluate the effect of remineralizing agents on micro shear bond strength of dentin.

\section{MATERIALS AND METHODS}

The materials used in the study are summarized in Table (1). A specially-fabricated cylindrical plastic mold of internal diameter $15 \mathrm{~mm}$ and $20 \mathrm{~mm}$ in height was fabricated. A separating medium was used to coat the internal surface of the mold. The mold was filled with self-curing acrylic resin, the base of the mold rested on a glass slab in order to obtain a flat smooth surface. Each tooth was embedded vertically in the mold while the acrylic resin still in the "dough stage" to the level of cemento-enamel junction of the tooth leaving the occlusal surface projecting above the surface of the mold.

The nano-hydroxyapatite (NHa) gel was applied on all dentine surfaces using micro brush and left for two minutes. That was repeated for five consecutive days. During this time the specimens stored in artificial saliva at $37^{\circ} \mathrm{C}$. In last time of application NHa gel was washed with distilled water for 15 seconds to ensure complete removal of excess and then air dried. Bonding agent applied according to the manufacturer instructions. Each adhesive bonding agent was applied according to its manufacturer's instructions on the dentin surface. Application of the nano composite in the cut pediatric tube parts, was done using periodontal probe $(1 \mathrm{~mm}$ diameter, by DENTSPLY $\left.{ }^{\circledR}\right)$, then curing for 30 seconds. The pediatric tubes were cut vertically and removed to obtain nano composite cylinders bonded to dentin surface (Figure 1).

Specimens were stored in distilled water at $37^{\circ} \mathrm{C}$ in an incubator with $100 \%$ humidity for different storage times (one day, one month, and three months) until micro-shear bond strength testing was done. Each mold was horizontally secured with tightening screws to the lower fixed compartment of a universal testing machine with add of $5 \mathrm{KN}$ and data recorded using computer software. A loop prepared from an orthodontic wire was wrapped around the bonded micro cylinder assembly as close as possible to the base of micro cylinder and aligned the loading axis of the upper movable compartment of the testing machine. A shearing load with tensile mode of force was applied via universal 
TABLE (1) Chemical composition and application procedure of the tested materials

\begin{tabular}{|c|c|c|c|}
\hline $\begin{array}{c}\text { Material } \\
\text { specification }\end{array}$ & Brand name & Composition & Manufacturer \\
\hline $\begin{array}{l}\text { Remineralizing } \\
\text { agent }\end{array}$ & $\begin{array}{l}\text { Hydroxy-apatite- } \\
\text { nano- crystals }\end{array}$ & $\begin{array}{c}\text { Calcium }\left(\mathrm{Ca}^{2+)} \text {, phosphate }\left(\mathrm{PO}_{4}^{3-}\right) \text {, hydroxide }(\mathrm{OH}-) \text {, hydrogen }\right. \\
\text {-phosphate }\left(\mathrm{HPO}_{4}^{2-}\right) \text {, water }(\mathrm{H} 2 \mathrm{O}) \text {, carbonate }\left(\mathrm{CO}_{3}^{2-}\right) \text {, and } \\
\text { trace constituents. }\end{array}$ & Nanostreams \\
\hline $\begin{array}{l}\text { Remineralizing } \\
\text { agent }\end{array}$ & Sodium -fluoride & $\begin{array}{l}\text { Sodium fluoride, sodium benzoate, purified water, phosphoric } \\
\text { acid, sodium saccharin, hydrofluoric acid, flavor, xylitol. }\end{array}$ & $\begin{array}{l}\text { Sultan Health } \\
\text { Care }\end{array}$ \\
\hline $\begin{array}{l}\text { Remineralizing } \\
\text { agent }\end{array}$ & $\begin{array}{c}\text { Floro - } \\
\text { hydroxyapatite }\end{array}$ & $\begin{array}{c}15 \% \mathrm{wt} \text { rod hydroxyapatite nanoparticles has been embedded into } \\
20 \% \mathrm{wt} \text {. poly ethylene oxide gel with the addition of } 1450 \mathrm{ppm} \\
\text { sodium fluoride nanoparticles }\end{array}$ & Nanostreams \\
\hline $\begin{array}{l}\text { One step self-etch } \\
\text { adhesive system }\end{array}$ & Adper Easy One & $\begin{array}{l}\mathrm{MDP}^{1^{*}} \text { phosphate monomer Dimethacrylate resins, } \mathrm{HEMA}^{2^{* * *}} \text {, } \\
\text { Vitrebond Copolymer, filler, initiators, silane, ethanol water }\end{array}$ & 3M ESPE \\
\hline $\begin{array}{l}\text { Two step etch and } \\
\text { rinse adhesive } \\
\text { system }\end{array}$ & Adper single bond & $\begin{array}{c}\text { Etchant 37\% H3PO4 } \\
\text { Adhesive Bis-GMA, HEMA, water, dimethacrylates, ethanol } \\
\text { methacrylate functional copolymer of polyacrylic and } \\
\text { polyitaconic acids, photo-initiators, nano- filler 10\%by weight } 5 \\
\text { nm spherical silica particles. }\end{array}$ & 3M ESPE \\
\hline $\begin{array}{l}\text { Nano filled } \\
\text { composite resin }\end{array}$ & Filtek z350xt & $\begin{array}{c}\text { Filler: zirconia/silica }(78,5 \% \text { by weight) Its matrix is composed } \\
\text { of Bis GMA }{ }^{3 * * *}, \text { UDMA }^{4 * * * *} \text {, and Bis-EMA }{ }^{5 * * * * *}, \text { with small } \\
\text { amount of TEGDMA }{ }^{* * * * * * *} \text {. The filler is zirconia /silica with } \\
\text { particle size range of } 0.06 \mu \mathrm{m} \text { to } 1.5 \mu \mathrm{m} \text {. }\end{array}$ & 3M ESPE \\
\hline Etching gel & Meta Etchant-37 & Phosphoric Acid 37\%, water, thickened, polymr and dye colorant. & Meta Biomed Co. \\
\hline
\end{tabular}

* MDP: methacryloyloxydecyl dihydrogen phosphate glycidyl methacrylate

${ }^{* *}$ HEMA: Hydroxy ethyl methacrylate

*** BIS-GMA: bisphenol glycol dimethacrylate

${ }^{* * * * *}$ UDMA: Urethane dimethacrylate

***** BIS-EMA: ethoxylated bisphenol a glycol dimethacrylate

******* TEGDMA: Triethylene glycol dimethacrylate.

testing machine at a cross-head speed of $0.5 \mathrm{~mm} /$ min. The relatively slow cross head speed was selected in order to produce a shearing force that resulted in deponing of micro cylinder along the substrate- adhesive interface. The load required for deponing was recoded in MPa. To determine the type of failure mode which could be adhesive, cohesive or mixed failure.

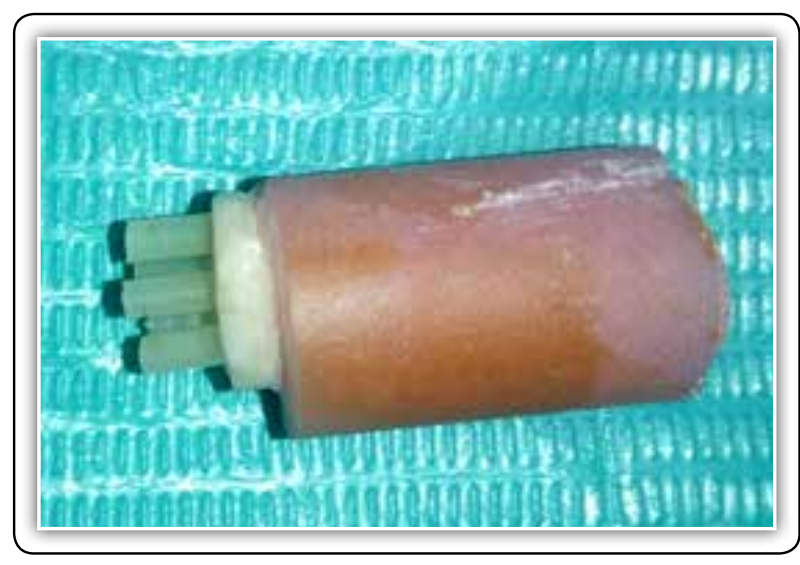

FIG (1) Resin composite samples 


\section{RESULTS}

Mean data of the micro-shear bond strength (MPa) were recorded and analyzed (Table 2). All statistical tests were done at a $95 \%$ level of significance using SPSS 20 software for Windows ${ }^{\circledR}$. 3-Way ANOVA was done to test statistical significance between the independent variables (Reminerilizing agents, adhesive bonding agents, and storage times).

Statistical analysis has shown that regardless of adhesive systems and storage times, it was found that fluoro-hydroxyapatite groups showed the highest bond strength mean value, followed by nano hydroxyapatite group, while the lowest was sodium fluoride group. There was statistically significant difference between the four studied groups, table (2) and figure (2).

It was found that mean shear bond strength value for the self-etch group was higher than that for the total etch one. There was a statistically significant increase in bond strength with self -etch than with total etch. As for the storage time, it was found that three months storage group had the highest shear bond strength mean value, followed by one month storage, whereas the lowest shear bond strength mean value was observed with the one day storage group. There was statistically significant difference between the three studied groups regarding bond strength at different storage times.

TABLE (2) Mean and standard deviation (SD) of micro-shear bond strength (MPa) of different remineralizing agents.

\begin{tabular}{|c|c|c|c|c|}
\hline \multicolumn{2}{|c|}{ Variable } & Mean & SD & P-value \\
\hline \multirow{4}{*}{$\begin{array}{c}\text { Treatment } \\
\text { groups }\end{array}$} & Nha & 17.42 & 1.01 & \\
\cline { 2 - 4 } & NaF & 15.07 & 2.74 & \multirow{2}{*}{0.027} \\
\cline { 2 - 4 } & Floro Ha & 19.01 & 2.10 & \\
\cline { 2 - 4 } & Control & 16.52 & 0.88 & \\
\hline
\end{tabular}

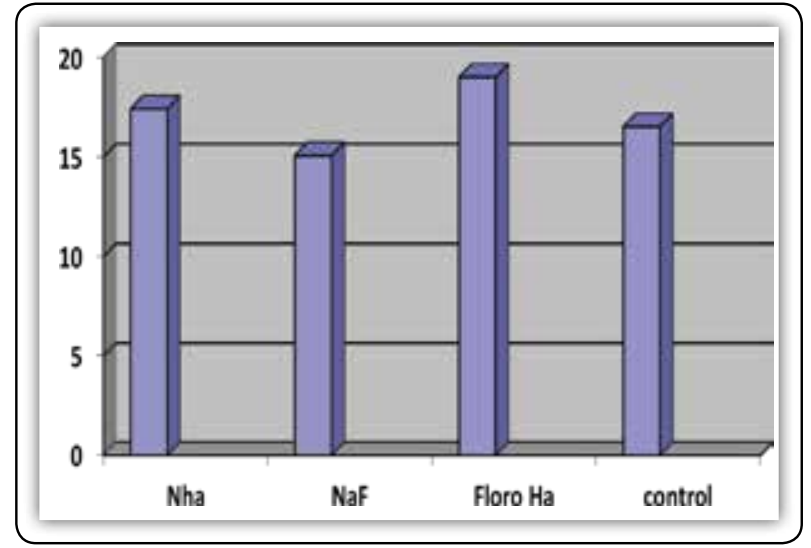

FIG (2) Histogram showing the mean microshear bond strength $(\mathrm{MPa})$ of remineralizing agents.

\section{Failure Mode:}

Mode of failure in all specimens was visually assessed. It was observed that the predominant failure was the cohesive type in the representing $54.4 \%$, while adhesive failure represent $36.7 \%$ and mixed failure represent $8.9 \%$. There was no cohesive failure in resin composite.

\section{DISCUSSION}

Hydroxyapatite (HAp) is one of the materials being utilized to treat dentin hypersensitivity. HAp is considered to be chemically-similar to enamel and dentin structure units. The ultra-structure of dental enamel consists of inorganic components distributed as rod of hexagonal HAp crystals, so it can be used in remediation of damaged enamel ${ }^{(11,12)}$. The use of HAp as a filler in dental restoration presents advantages that include intrinsic radio-opaque response, enhanced polishing ability and improved wear resistance ${ }^{(13)}$. Dentin remineralization is more complex than enamel remineralization, even so dentine remineralization is clinically significant since it would contribute to the minimally invasive management of dentine caries, root caries and dentine hypersensitivity. The mode of action of HAp in treatment of hypersensitivity is occlusion of dentinal tubules and decreasing dentinal fluid movement ${ }^{(14,15)}$. 
The results of the present study showed that floro-hydroxyapatite group had the highest bond strength mean value (19.01 MPa) followed by nanohydroxyapatite (17.42 $\mathrm{MPa})$, while the lowest bond strength was in sodium fluoride group (15.07 MPa). This might be because hydroxyapatite materials have the potential to biomimetically remineralize dentin by replacing matrix and water with apatite crystallites. This exchange would increase mechanical properties and inhibit water-related hydrolysis, thus enhancing the bond strength with time. The preservation of hydroxyapatite within the submicron hybrid layer may serve as a receptor for additional chemical bonding ${ }^{(16,17)}$. The presence of calcium and phosphate ions correlate to this chemical bonding. Also fluoride component of the nano hydroxyapatite increases the mineral content of the dentin on the expense of pretentious material of dentin or its water content. This result agrees with Mahmoud et al, 2015, who found that Synsetic compound of fluoro-hydroxyapatite increases bond strength to dentin rather than hydroxyapatite itself. This is also in agreement with the studies done by Garcia et al, Chermont et al, and Gupta T et al, who concluded that nano-hydroxyapatite has a beneficial effect on the shear bond strength to dentin. This was in disagreement with Sarac D et al, who concluded that NHa treatment of dentin caused a decrease in its bond strength. This difference may be due to differences in the materials or methods that were used.

Regarding sodium fluoride the bond strength values were the lowest among all tested groups. This might be due to the fact that sodium fluoride did not form organo-metallic complexes with dentin, resulting in an interface that was quite weak and acid resistant causing decreased in bond strength. This is in agreement with Diamanti et al, who concluded that sodium fluoride has a deleterious effect on shear bond strength of dentin. The results of this study showed that the self-etch adhesive group had a higher bond strength mean values $(20.38 \mathrm{MPa})$ than total etch group (13.63 MPa). This can be because total etch adhesive system promotes the removal of a large part of superficial previously remineralized component. On the other hand, the decrease in the acidity in self-etch reduce this mineral component removal with the simultaneous demineralization and infiltration of self-etch adhesive into dentin. These two simultaneous actions lead to a shallow but uniform resin-infiltrated dentin layer through which the residual hydroxyapatite remains available for chemical reaction ${ }^{(18)}$. This is in agreement with Devabhaktuni et al, and Sabatini et al, who concluded that self-etch adhesives had a better bond strength values with previously remineralized dentin than total etch adhesives.

Regarding the control group, self-etch adhesive system had a lower bond strength values than total etch. This may be due to the reduced etching potential of acidic monomers on the hybrid layer or because of non-cured hydrophilic components due to bonding area deterioration when these selfetching adhesives are used. Another possible cause may be the smear layer removal after etching with total etch adhesive and before adhesive application could produce a more durable and realistic bond to dentin. ${ }^{(19)}$. The close values of total etch and selfetch may be due to an Adper Easy One etching effect that approached that of acid etching with 35\% phosphoric acid, suggesting its efficacy and adhesive potential. This result agree with Van Meerbeek et al, who found that total etch Adeper Single Bond had a little higher bond strength to dentin than self-etch Adeper Easy One.

The result of this study revealed that 3 months storage time had the highest bond strength mean value $(17.565 \mathrm{MPa})$, followed by 1 month storage time $(17.15 \mathrm{MPa})$, while the lowest mean value was 1 day storage time (15.01 MPa). This may be because for both self-etch and total etch there is an increase in bond strength with time. This might be because it is impossible for resin monomers to completely displace water within the extra-fibrillar 
and intra-fibrillar compartments of a demineralized collagen matrix, and infiltrate the collagen network completely. But relatively, the hydroxyapatite materials have the potential to biomimetically remineralize dentin by replacing matrix and water with apatite crystallites. This exchange would increase mechanical properties and inhibit waterrelated hydrolysis, thus enhancing the bond strength with time. The preservation of hydroxyapatite within the submicron hybrid layer may serve as a receptor for additional chemical bonding with time. The presence of calcium and phosphate ions correlate to this chemical bonding ${ }^{(20)}$. This is in agreement with Gupta et al, who found that the increase in storage time of dentin treated samples with hydroxyapatite compounds up to six months had led to an increase in micro-shear bond strength.

The results of the present study revealed that cohesive failure was prevalent $(54.4 \%)$, followed by adhesive failure $(36.7 \%)$ while mixed failure provided the lowest mean value $(8.9 \%)$. This finding does necessarily reflect the true interfacial bond strength between the adhesive resin and the material due to high mechanical properties of nanofilled composite.

\section{CONCLUSION}

Within the limitations of the present study it can be concluded that floro-hydroxyapatite and nanohydroxyapatite had a positive effect on micro-shear bond strength to dentin, whereas sodium fluoride had a negative effect. The type of adhesive had an obvious effect on the dentin bond strength, where self-etch affected bond strength to dentin positively more than total etch. Storage time increase had a positive effect on the micro-shear bond strength of dentin with floro-hydroxyapatite and nanohydroxyapatite, but it had an adverse effect on the dentin bond strength with sodium fluoride and control groups.

\section{REFERENCES}

1. Pashely D, Swift E. Dentin bonding. J esthet Restor Dent. 2008; 20(3):153-4.

2. Lin J, Zheng W, Liu P, Zhang N, Lin, Fan Y, Gu X, Vollrath $\mathrm{O}, \mathrm{Mehl} \mathrm{C}$. Influence of casein phosphopetide-amorphous calcium phosphate application, smear layer removal, and storage time on resin-dentin bonding. J zus.B.2014; 15-7.

3. Soeno K, Taira Y, Matsumura H, Atsuta M. Effect of desensitizers on bond strength of adhesive luting agents to dentin. J of Oral Rehabil.2001; 28:1122-28.

4. Antoucci J, Odonnell J, Schumacher G, Skrtic D. Amorphous calcium phosphate composites and their effect on composite-adhesive-dentin. J Adhes Sci Technol.2009; 1, 23 (7):1133-47.

5. Pepla E, Besharat L, Palaia G, Tenore G, Migliau G. Nano-hydroxyapatite and its applications in preventive, restorative and regenerative dentistry. Eur j Oral Sci.2014; 20:108-14

6. Watanabe J, Akashi. Formation of hydroxyapatite provides a tunable protein reservoir within porous polyester membranes. J Dent Res.2007; 8:2288-93.

7. Kim H, Kong Y, Bae C. Sol-gel derived fluor hydroxyapatite biocoatings on zirconia substrate. J Biomaterials 2004; 25:2919-26.

8. Parolia A, Kundabala M, Mohan M. Management of dentinal hypersensitivity: A review. J Calif Dent Assoc 2011; 39:167-79.

9. Villela-Rosa A, Gonçalves M, Orsi I. Shear bond strength of self-etch and total-etch bonding systems at different dentin depths. Braz Oral Res. 2011; 25(2):109-15.

10. Ivanyi I, Balogh A, Rosivall L. In vivo examination of the scotch bond multi-purpose dental adhesive system in rat (vital microscopic study). Oper Dent. 2000, 25; 418-23.

11. Poggio C, Lombardini M, Colombo M, Bianchi S. Impact of two toothpastes on repairing enamel erosion produced by a soft drink: An AFM in vitro study. J Dent, 2010(38)868-74.

12. Tschoppe P, Zandim D, Martus P, Kielbassa, A. Enamel and dentine remineralization by nanohydroxyapatite toothpastes. J Dent, 2011 (39), 430- 37.

13. Domingo C, Arcís R, Osorio E, Toledano M. Hydrolytic stability of experimental hydroxyapatite-filled dental composite materials. J Dent Mater, 2003 (19)478-86.

14. Featherstone JD. Dental caries: a dynamic disease process. Aust Dent J. 2008; 53(3):286-91. 
15. Liuyun J, Yubao, Chengdong X. Preparation and biological properties of a novel composite scaffold of nano-hydroxyapatite/chitosan/carboxymethyl cellulose for bone tissue engineering. J Biomed Sci Eng, 2009 (16) 65.

16. Garcia R, Giannini M, Sato T, Tagami J. Effect of dentin desensitizers on resin cement bond strengths. Rev Sul Bras Odontol 2015; 12:14-22.

17. Chermont A, Andrade A, Shimaoka A, Carvalho R. Effect of prior use of desensitizing agents on bond strength of adhesive systems to human dentin. Pinnacle Med Med Sci 2015; $2: 1-8$.
18. Mahmoud N. Remineralization potential of hydroxyapatite and fluoride nano particles of on dentin. Egypt dent J, 2015; 61(2): 1872 .

19. Carvalho R, Chersoni S, Frankenberg R, Pashey D, Prati C, Tay F. A challenge to the convencional widsdom that simultaneous etching and resin infiltration always occurs in self-etch adhesives. J Biomaterials. 2005; 26(9):1035-42.

20. Garcia R, Goes M, Giannini M. Effect of water storage on bond strength of self-etching adhesives to dentin. J Contemp Dent Pract 2007 ;(7)46-53. 